\title{
HUBUNGAN ASUPAN KARBOHIDRAT SEDERHANA, ASUPAN SERAT DAN KEBIASAAN OLAHRAGA DENGAN INDEKS MASSA TUBUH KARYAWAN REKTORAT UNIVERSITAS JENDERAL SOEDIRMAN (UNSOED)
}

\author{
The Relationship Between Simple Carbohydrates Intake, Dietary Fiber \\ Intake, And Excercise Habbits With Body Mass Index Of Head Official \\ Employee Jenderal Soedirman University \\ Noor Cherinawati ${ }^{1}$, Saryono $^{2}$, Yovita Puri Subardjo ${ }^{1}$ \\ ${ }^{1}$ Program Studi Ilmu Gizi Fakultas Ilmu-Ilmu Kesehatan Universitas Jenderal Soedirman. ${ }^{2}$ Jurusan \\ keperawatan Fakultas Ilmu-Ilmu Kesehatan Universitas Jenderal Soedirman. \\ noorcheryna@gmail.com
}

\begin{abstract}
This study aim to determine correlation between simple carbohydrates intake, dietary fiber intake, and excercise habbits on body mass index (BMI) of employee. This study used a cross-sectional method. As many as 63 peoples were selected as samples using purposive sampling method. Simple carbohydrate intake and fiber intake were measured using a $2 \times 24$ hour recall method, exercise habits were measured using exercise habits questionnaires. BMI was measured using digital scales and microtoise. The result showed an average simple carbohydrates intake $37.8 \pm 33.3 \mathrm{~g} /$ day , dietary fiber intake $9.7 \pm 4.1 \mathrm{~g} /$ day, excercise habbits $63.6 \pm$ 77.7 minutes/week. The pearson correlation test showed insignificant relationship between simple carbohydrates intake, dietary fiber intake, and excercise habbits with BMI $(p=0.976,0.871$ and 0.454$)$. Simple carbohydrates intake, dietary fiber intake, and excercise habbits did not relate with BMI head official employee Unsoed.

Keywords : simple carbohydrates, dietary fiber, excercise habbits, body mass index.
\end{abstract}

\begin{abstract}
ABSTRAK
Penelitian ini bertujuan untuk mengetahui hubungan asupan karbohidrat sederhana, asupan serat, dan kebiasaan olahraga dengan Indeks Massa Tubuh (IMT) karyawan. Penelitian ini menggunakan metode cross-sectional. Sampel berjumlah 63 orang dipilih menggunakan metode purposive sampling. Data asupan karbohidrat sederhana dan serat diukur menggunakan metode recall 2x24 jam, data kebiasaan olahraga diukur menggunakan kuesioner kebiasaan olahraga. IMT diukur menggnakan timbangan digital dan microtoice. Hasil penelitian menunjukan rata-rata asupan karbohidrat sederhana 37,8 $\pm 33,3 \mathrm{~g} /$ hari; rata-rata asupan serat 9,7 \pm 4,1 g/hari ; rata-rata kebiasaan olahraga 63,6 \pm 77,7 menit/minggu. Hasil uji korelasi pearson diperoleh hubungan tidak signifikan antara asupan karbohidrat sederhana, asupan serat, dan kebiasaan olahraga dengan IMT $(\mathrm{p}=0,976 ; 0,871$ dan 0,454$)$. Asupan karbohidrat sederhana, asupan serat, dan kebiasaan olahraga tidak berhubungan dengan IMT.
\end{abstract}

Kata kunci : karbohidrat sederhana, serat, kebiasaan olahraga, indeks massa tubuh

\section{PENDAHULUAN}

Prevalensi obesitas pada orang dewasa setiap tahun mengalami peningkatan. Menurut data RISKESDAS pada tahun 2010 obesitas prevalensi obesitas mencapai $11,7 \%$ dan meningkat menjadi $15,4 \%$ pada tahun 2013.
Prevalensi obesits cenderung lebih tinggi pada kelompok penduduk dewasa berumur diatas 35 tahun pada seseorang yang bekerja sebagai PNS/TNI/Polri/dan

Pegawai. (Kemenkes RI (2010) dan Kemenkes RI (2013)). 
Penelitian yang dilakukan oleh Lestari (2017) menyatakan bahwa sebagian besar $(56,3 \%)$ karyawan di salah satu Universitas di Jakarta mengalami obesitas. Obesitas dikategorikan jika seseorang memiliki Indeks Massa Tubuh $\left(\right.$ IMT) $\geq 25 \mathrm{~kg} / \mathrm{m}^{2}$ (Kemenkes RI, 2013). Penelitian yang dilakukan oleh Subardjo et al. (2018) IMT berhubungan dengan beberapa profil sindroma metabolik masyarakat usia produktif posbindu penyakit tidak menular Kabupaten Banyumas. Profil sindroma metabolik dapat digunakan untuk memrediksi penyakit jantung dan penyakit degeneratif lainnya seperti diabetes.

Obesitas dapat dikendalikan dengan cara mengkonsumsi karbohidrat sederhana dan serat sesuai dengan anjuran. Konsumsi karbohidrat sederhana secara berlebihan dapat meningkatkan kelebihan asupan energi, berat badan tidak ideal, dan kurangnya asupan gizi lainnya seperti serat (Davy et al., 2014). Serat membuat seseorang kenyang lebih lama sehingga dapat menjadi faktor penting dalam mengatasi obesitas (Slavin, 2005). Obesitas juga dapat dicegah dengan cara meningkatkan aktivitas fisik. Aktivitas fisik secara teratur seperti olahraga dapat memperlancar metabolisme tubuh sehingga mengurangi penimbunan lemak tubuh (Mappaompo, 2010).

Karyawan universitas cenderung memiliki aktivitas fisik yang rendah karena sebagian menghabiskan $75 \%$ waktu bekerja untuk diam ditempat (Fountaine et al., 2014). Selain itu karyawan juga dapat dengan mudah mengakses makanan dan minuman karena lokasi bekerja banyak dijumpai kantin maupun rumah makan sehingga sangat memungkinkan karyawan memiliki IMT tidak normal (Davy et al., 2014).

\section{METODE}

Penelitian ini menggunakan metode cross-sectional dilakukan di Unsoed, Purwokerto. Sampel berjumlah 63 orang yang dipilih menggunakan metode purposive sampling. Data asupan karbohidrat sederhana dan asupan serat diukur menggunakan metode recall $2 \times 24$ jam, data kebiasaan olahraga diukur menggunakan kuisioner kebiasaan olahraga. IMT diukur menggnakan timbangan digital dan microtoice. Data dianalisis menggunakan korelasi pearson product momen 


\section{HASIL}

\section{Analisis Univariat}

Tabel 1. Rata-Rata IMT berdasarkan Karakteristik Reponden

\begin{tabular}{|c|c|c|c|}
\hline Karakteristik Responden & $\mathbf{n}$ & $\%$ & Rata-Rata IMT \\
\hline \multicolumn{4}{|l|}{ Jenis Kelamin } \\
\hline Laki-Laki & 34 & 54 & 26,2 \\
\hline Perempuan & 29 & 46 & 25,6 \\
\hline \multicolumn{4}{|l|}{ Usia } \\
\hline$\leq 35$ tahun & 22 & 34,9 & 26,0 \\
\hline$>35$ tahun & 41 & 65,1 & 25,9 \\
\hline \multicolumn{4}{|l|}{ Pendidikan } \\
\hline Sekolah menengah & 10 & 16 & 26,0 \\
\hline Sekolah tinggi & 53 & 84 & 25,9 \\
\hline \multicolumn{4}{|l|}{ Asupan energi } \\
\hline Kurang $(<80 \%)$ & 52 & 83 & 26,4 \\
\hline Baik (80-110\%) & 10 & 16 & 24,0 \\
\hline Lebih $(>110 \%)$ & 1 & 2 & 23,2 \\
\hline \multicolumn{4}{|l|}{ Asupan karbohidrat sederhana } \\
\hline Baik $(\leq 50 \mathrm{~g} /$ hari $)$ & 50 & 79,4 & 26,0 \\
\hline Lebih > 50 g/hari) & 13 & 20,6 & 25,9 \\
\hline \multicolumn{4}{|l|}{ Asupan serat } \\
\hline Kurang (<30 g/hari) & 63 & 100 & 25,9 \\
\hline Baik ( $\geq 30$ g/hari) & 0 & 0 & 0 \\
\hline \multicolumn{4}{|l|}{ Kebiasaan olahraga } \\
\hline \multicolumn{4}{|l|}{ Kurang (<150 menit/minggu) } \\
\hline 0 menit/ minggu & 24 & 38,1 & 25,7 \\
\hline $1-<75$ menit/minggu & 20 & 31,7 & 25,3 \\
\hline $75-<150$ menit/minggu & 10 & 15,9 & 28,7 \\
\hline Baik ( $\geq 150$ menit/minggu) & 9 & 14,3 & 24,7 \\
\hline
\end{tabular}

Tabel 1. menunjukan bahwa setiap karakteristik responden tidak ada perbedaan antara kategori jenis kelamin, usia, dan pendidikan dengan rata-rata IMT responden. Sebanyak $83 \%$ responden memiliki asupan energi yang kurang tetapi memiliki rata-rata IMT paling besar dibandingkan dengan responden yang memiliki asupan energi yang baik maupun lebih.
Asupan karbohidrat sederhana responden sebagian kecil (20,5\%) telah melebihi pedoman gizi seimbang yaitu > 50 g/hari, rata-rata IMT responden yang memiliki asupan karbohidrat sederhana berlebih yaitu $25,9 \mathrm{~kg} / \mathrm{m}^{2}$. Semua responden memiliki asupan serat yang kurang. Sebagian besar responden $(38,1 \%)$ tidak pernah berolahraga memiliki rata-rata IMT $25,3 \mathrm{~kg} / \mathrm{m}^{2}$.

Tabel 2. Distribusi IMT responden

\begin{tabular}{rcc}
\hline \multirow{2}{*}{ IMT } & \multicolumn{2}{c}{ Frekuensi } \\
\cline { 2 - 3 } & n & \% \\
\hline $\begin{array}{r}18,5-24,9 \text { (Gizi baik) } \\
25-26,9 \text { (Gizi lebih) }\end{array}$ & 31 & 49,2 \\
$\geq 27$ (Obesitas) & 11 & 17,5 \\
\hline Total & 21 & 33,3 \\
\hline
\end{tabular}


Sebanyak 33,3\% responden memiliki status gizi obesitas yang diukur menggunakan IMT. Rata-rata IMT responden yaitu $25,9 \mathrm{~kg} / \mathrm{m}^{2}$ dengan IMT paling kecil yaitu $19,5 \mathrm{~kg} / \mathrm{m} 2$ dan IMT paling besar yaitu $36 \mathrm{~kg} / \mathrm{m}^{2}$.

Tabel 3. Rata-Rata Asupan Karbohidrat Sederhana, Asupan Serat dan Kebiasaan Olahraga berdasarkan Status Gizi (IMT)

\begin{tabular}{lcccc}
\hline \multicolumn{1}{c}{ Status Gizi } & $\begin{array}{c}\text { Karbohidrat } \\
\text { Sederhana }\end{array}$ & Serat & $\begin{array}{c}\text { Kebiasaan } \\
\text { Olahraga }\end{array}$ & Energi \\
\hline Gizi baik $(18,5-24,9)$ & 36,1 & 9,7 & 60,4 & 67,6 \\
Gizi lebih dan obesitas $(\geq 25)$ & 39,4 & 9,0 & 66,1 & 62,5 \\
\hline
\end{tabular}

Data pada Tabel 3. menunjukan bahwa seseorang yang memiliki status gizi baik mengonsumsi karbohidrat sederhana lebih rendah, serat lebih banyak, asupan energi lebih banyak dan kebiasaan olahraga lebih jarang daripada responden yang memiliki status gizi lebih dan obesitas.

\section{Analisis Bivariat}

Tabel 4. Hubungan Asupan Karbohidrat Sederhana, Asupan Serat, Dan Kebiasaan Olahraga dengan

\begin{tabular}{lcccc}
\multicolumn{5}{c}{ IMT } \\
Variabel & Mean & SD & r & p value \\
\hline Karbohidrat Sederhana & 37,8 & 33,3 & $-0,04$ & 0,976 \\
Serat & 9,7 & 4,1 & 0,021 & 0,871 \\
Kebiasaan Olahraga & 63,6 & 77,7 & 0,096 & 0,454 \\
\hline
\end{tabular}

Hasil penelitian menunjukan bahwa tidak terdapat hubungan signifikan asupan karbohidrat sederhana, asupan serat, dan kebiasaan olahraga dengan IMT karyawan rektorat Universitas Jenderal Soedirman. Dari hasil analisis di peroleh nilai $\mathrm{p}$ value $>0,05$ ( nilai $\mathrm{p}=0,976 ; 0,871 ; 0,454)$.

\section{PEMBAHASAN}

\section{Hubungan Asupan Karbohidrat} Sederhana dengan IMT
Data pada Tabel 1. menunjukan bahwa rata-rata IMT responden yang mengonsumsi karbohidrat sederhana sesuai anjuran dan melebihi anjuran hampir sama yaitu $26,0 \mathrm{~kg} / \mathrm{m}^{2}$ dan 25,6 $\mathrm{kg} / \mathrm{m}^{2}$. Hasil analisis uji statistik menggunakan korelasi pearson diperoleh nilai $\mathrm{p}>0,05(0,976)$ yang artinya tidak terdapat hubungan antara asupan karbohidrat sederhana dengan IMT karyawan rektorat Unsoed. Penelitian ini sejalan dengan penelitian Hartman et al. 
(2017) yang menyatakan tidak terdapat hubungan asupan karbohidrat sederhana dari minuman manis dengan IMT dan penambahan berat badan wanita dengan status gizi lebih dan obesitas. Penelitian lain yang sejalan dengan penelitian ini yaitu penelitian yang dilakukan oleh Jaminah dan Mahmudiono (2018) yang menyatakan bahwa asupan karbohidrat tidak berhubungan signifikan dengan IMT karyawan instalasi gizi RSUD dr. Soetomo. IMT seseorang dapat meningkat bukan hanya karena memiliki asupan karbohidrat berlebih, seseorang yang memiliki asupan karbohidrat dibawah kebutuhan juga dapat memiliki IMT berlebih pada karyawan gizi RSUD dr. Soetomo.

Sebagian besar responden berusia $>35$ tahun $(65,1 \%)$ dengan rata-rata usia responden yaitu 41 tahun. Penelitian yang dilakukan oleh Lührmann et al. (2009) menyatakan bahwa semakin bertambahnya usia dan aktivitas fisik yang rendah menyebabkan penurunan energi expenditure. Penurunan energi expenditure dapat meningkatkan berat badan karena rendahnya tingkat oksidasi lemak, pengeluaran energi yang rendah, aktivitas simpatik yang rendah, dan aktivitas spontan yang rendah sehingga energi yang dikonsumsi oleh seseorang sebagian banyak disimpan sebagai kelebihan energi (Galgani dan Ravussin, 2009).

Penelitian ini tidak sejalan dengan Wang et al. (2013) yang menyatakan bahwa IMT meningkat secara bersamaan dengan meningkatnya asupan gula tambahan pada orang dewasa di wilayah Minnesota Amerika Serikat. Asupan gula tambahan terutama dari minuman manis dapat meningkatkan IMT karena akan menyebabkan kelebihan energi serta tidak memberikan efek yang mengenyangkan.

Data pada Tabel 3. menunjukan bahwa responden yang memiliki status gizi baik cenderung mengonsumsi karbohidrat sederhana lebih rendah yaitu 36,1 g/hari jika dibandingkan dengan responden yang memiliki status gizi lebih dan obesitas (39,4 g/hari). Tabel 1. menunjukan bahwa sebanyak 20,6\% responden memiliki asupan karbohidrat sederhana berlebih dengan rata-rata IMT sebesar $25,9 \mathrm{~kg} / \mathrm{m}^{2}$. Data recall makanan menunjukan bahwa responden tersebut mengonsumsi banyak karbohidrat sederhana disetiap waktu makan. Pada pagi dan malam hari responden cenderung mengonsumsi minuman manis seperti kopi, teh atau jus buah. Responden mengonsumsi kue-kue pada saat selingan makan pagi dan siang hari. Pada saat makan siang responden cenderung mengonsumsi lauk yang diolah 
menggunakan banyak gula seperti tahu bacem, tempe bacem, gudeg dan makanan yang menggunakan sambal kacang.

\section{Hubungan Asupan Serat Dengan}

\section{Indeks dengan Massa Tubuh}

Semua responden memiliki asupan serat rata-rata dibawah kebutuhan asupan serat harian $(<33$ g/hari). Rata-rata responden mengonsumsi serat sebanyak 9,7 g/hari $\pm 4,1$ g/hari. Hasil analisis uji statistik menggunakan korelasi pearson diperoleh nilai $\mathrm{p}>0,05(0,871)$, artinya tidak terdapat hubungan antara asupan serat dengan IMT karyawan rektorat Unsoed. Penelitian ini sejalan dengan Shanti et al. (2017) yang menyatakan bahwa tidak terdapat hubungan antara konsumsi serat dengan IMT wanita usia subur suku madura di kota Malang. Seluruh responden memiliki asupan serat dibawah rekomendasi kebutuhan, rata-rata asupan serat responden yaitu 7,16 $\pm 3,13$ g/hari. Tabel 3. menunjukan bahwa karakteristik responden pada penelitian ini cenderung memiliki rata-rata konsumsi serat sebanding dengan asupan energi yang dikonsumsi, sehingga asupan serat tidak berhubungan signifikan dengan IMT. Hal ini dapat disebabkan karena sayur sebagai salah satu sumber serat dihidangkan bersamaan dengan makanan pokok dan lauk pauk lainnya (Hermina dan Prihatini, 2016).
Penelitian ini tidak sejalan dengan penelitian yang dilakukan oleh Slavin (2008) yang menyatakan bahwa serat menyediakan makanan dalam porsi besar dan lebih mengenyangkan. Selain itu makanan yang banyak mengandung serat akan membuat intensitas dan waktu pengunyahan lebih lama dan menurunan konsumsi makanan sehingga energi yang dikonsumsi lebih sedikit. Penelitian ini juga tidak sejalan dengan Van de Vijner et al. (2009) yang menyatakan bahwa terdapat hubungan terbalik antara orang yang mengonsumsi biji-bijian utuh dan serat makanan dengan IMT. Menurut Hadrevi et al. (2017) terdapat perbedaan antara konsumsi serat pada orang yang memiliki status gizi normal dengan orang yang mengalami obesitas.

Data pada Tabel 3. menunjukan bahwa responden yang memiliki status gizi baik cenderung mengonsumsi serat lebih banyak yaitu 9,7 g/hari dibandingkan dengan responden yang memiliki status gizi lebih dan obesitas. Rata-rata asupan serat responden yang memiliki status gizi lebih dan obesitas yaitu 9,0 g/hari. Hasil penelitian ini didukung oleh penelitian yang dilakukan oleh Kustiyah et al. (2013) yang menyatakan bahwa tidak ada hubungan antara asupan serat IMT, tetapi seseorang yang memiliki status gizi normal cenderung mengonsumsi serat 
lebih banyak dari pada orang yang memiliki status gizi lebih.

\section{Hubungan Kebiasaan Olahraga dengan IMT}

Rata-rata kebiasaan olahraga responden yaitu 63,6 menit/minggu. Data pada Tabel 3. menunjukan bahwa responden yang memiliki status gizi normal memiliki rata-rata kebiasaan olahraga 60,4 menit/minggu, lebih kecil jika dibandingkan dengan rata-rata kebiasaan olahraga responden yang memiliki status gizi lebih dan obesitas yaitu 66,1 menit/minggu. Hasil analisis uji statistik menggunakan rank spearman diperoleh nilai $p>0,05$ yang artinya tidak terdapat hubungan antara kebiasaan olahraga dengan IMT pada karyawan rektorat Unsoed. Hasil penelitian ini sejalan dengan Martin et al. (2016) yang menyatakan bahwa tidak ada hubungan signifikan antara lama waktu olahraga perminggu dengan IMT orang dewasa di Madrid Spanyol. Hal ini dapat dijelaskan oleh penelitian yang dilakukan oleh Kruger et al. (2008) menyatakan bahwa seseorang memiliki kelebihan berat badan dan berniat menurunkan berat badan cenderung melakukan olahraga teratur 2,8 kali (perempuan) dan 2.2 kali (laki-laki) lebih besar pada laki-laki dari pada seseorang yang tidak berniat menurunkan berat badan.
Penelitian ini tidak sejalan dengan penelitian Lee et al. (2010) yang menyatakan bahwa terdapat hubungan signifikan antara aktivitas fisik dengan berat badan. Seseorang yang melakukan aktivitas fisik secara teratur selama 60 menit perhari dapat mempertahankan berat badan normal selama 13 tahun.

Tabel 1. menunjukan bahwa responden yang memiliki kebiasaan olahraga yang baik ( $\geq 150 \mathrm{menit} / \mathrm{minggu}$ ) cenderung memiliki IMT lebih rendah yaitu $24,7 \mathrm{~kg} / \mathrm{m}^{2}$ dibandingkan dengan responden yang tidak pernah berolahraga. Rata-rata IMT responden yang tidak pernah berolahraga yaitu sebesar 25,7 $\mathrm{kg} / \mathrm{m}^{2}$. Menurut Swift et al. (2014) seseorang harus melakukan olahraga 150 menit/minggu untuk mempertahankan berat badan dan olahraga 200 menit/minggu untuk menurunkan berat badan. Data pada Tabel 1. juga menunjukan responden yang memiliki status gizi lebih memiliki kebiasaan olahraga $<75$ menit/minggu sedangkan responden yang mengalami obesitas melakukan olahraga $75 \quad-\quad<150$ menit/minggu. Hal tersebut disebabkan responden yang merasa gemuk berusaha menurunkan berat badan dengan cara berolahraga, namun olahraga yang dilakukan responden belum maksimal. 


\section{KESIMPULAN}

Tidak terdapat hubungan antara asupan karbohidrat sederhana, asupan serat, dan kebiasaan olahraga dengan IMT karyawan rektorat Unsoed. Walaupun asupan karbohidrat sederhana, asupan serat dan kebiasaan olahraga tidak berhubungan dengan IMT, namun responden yang memiliki status gizi baik cenderung memiliki asupan karbohidrat sederhana lebih rendah, asupan serat lebih tinggi serta responden yang memiliki kebiasaan olahraga baik cenderung memiliki IMT lebih rendah daripada responden yang mempunyai kebiasaan olahraga yang buruk.

\section{SARAN}

$\begin{aligned} & \text { Sebaiknya karyawan Unsoed } \\ & \text { dapat membatasi asupan karbohidrat }\end{aligned}$ sederhana dengan cara tidak mengonsumsi makanan yang banyak mengandung karbohidrat sederhana pada setiap waktu makan. Kedua, sebaiknya responden menerapkan porsi sekali makan pedoman gizi seimbang 2014 agar tidak terjadi peningkatan energi yang berasal dari makanan lainnya seperti pokok dan lauk yang dikonsumsi secara bersamaan dengan sumber serat. Selain itu karyawan sebaiknya membiasakan olahraga mininal 150 menit/minggu untuk menpertahankan berat badan dan 200 menit/minggu untuk menurunkan berat badan.

\section{DAFTAR PUSTAKA}

Davy, B. M., You, W., Almeida, F., Wall, S., Harden, S., Comber, D. L., \& Estabrooks, P. A. 2014. Peer Reviewed: Impact of Individual and Worksite Environmental Factors on Water and Sugar-Sweetened Beverage Consumption Among Overweight Employees. Preventing chronic disease, 11 .

Fountaine, C.J., Piacentini, M. and Liguori, G.A., 2014. Occupational sitting and physical activity among university employees. International journal of exercise science, 7(4), p.295.

Galgani, J. and Ravussin, E., 2009. Energy metabolism, fuel selection and body weight regulation. International journal of obesity, 32(S7), p.S109.

Hadrévi, J., Søgaard, K. and Christensen, J.R., 2017. Dietary Fiber Intake amongg Normal-Weight and Overweight Female Health Care Workers: An Exploratory Nested Case-Control Study within FINALE-Health. Journal of nutrition and metabolism, 2017.

Hartman, T.J., Haardörfer, R., Greene, B.M., Parulekar, S. and Kegler, M.C., 2017. Beverage Consumption Patterns among Overweight and Obese African American Women. Nutrients, 9(12), p. 1344 .

Hermina and Prihatini, S., 2016. Fruits And Vegetables Consumption Of Indonesian Population In The Context Of Balanced Nutrition: A Further Analysis of Individual Food Consumption Survey (SKMl) 2014. Buletin Penelitian Kesehatan, 44(3), pp.205-218.

Jaminah, J. and Mahmudiono, T., 2018. Relationship Between Knowledge, Physical Activity with Body Mass Index of Woman Employass at the Nutrition Instalation Dr. Soetomo Hospital. Jurnal Berkala Epidemiologi, 6(1), pp.13-24.

Kementerian Kesehatan, R. I. 2010. Riset Kesehatan Dasar. Badan Penelitian dan Pengembangan Kesehatan Departemen Kesehatan Republik Indonesia: Jakarta 
Kementerian Kesehatan, R. I. 2013. Riset Kesehatan Dasar. Badan Penelitia dan Pengembangan Kesehatan Departemen Kesehatan Republik Indonesia : Jakarta.F

Kruger, J., Yore, M.M. and Kohl, H.W., 2008. Physical activity levels and weight control status by body mass index, among adults-National Health and Nutrition Examination Survey 19992004. International Journal of Behavioral Nutrition and Physical Activity, 5(1), p.25.

Kustiyah, L., Widhianti, M.U. and Dewi, M., 2014. Hubungan asupan serat dengan status gizi dan profil lipid darah pada orang dewasa dislipidemia. Jurnal Gizi dan Pangan, 8(3), pp.195-200.

Lee, I.M., Djoussé, L., Sesso, H.D., Wang, L. and Buring, J.E., 2010. Physical activity and weight gain prevention. Jama, 303(12), pp.11731179.

Lestari, D. I. 2017. Pengaruh Kebiasaan Merokok Terhadap Obesitas dan Overweight pada Karyawan Universitas di Jakarta. Jurnal Muara Sains, Teknologi, Kedokteran dan Ilmu Kesehatan, 1(1).

Lührmann, P.M., Bender, R., Edelmann-Schäfer, B. and Neuhäuser-Berthold, M., 2009. Longitudinal changes in energy expenditure in an elderly German population: a 12-year followup. European journal of clinical nutrition, 63(8), p.986.

Mappaompo, M. A. 2010. Obesitas dan Olahraga. Jurnal ILARA, 1(2), 10-16.

Martín, I.S.M., Vilar, E.G. and Barato, V.P., 2016. Exercise and Body Mass Index: are those two parameters related in adults?. Journal of Negative and No Positive Results: JONNPR, 1(1), pp.3641.
Shanti, K.M., Andarini, S., Mutiyani, M., Wirawan, N.N. and Rahmawati, W., 2017. Asupan Serat dan IMT Wanita Usia Subur Suku Madura di Kota Malang. Indonesian Journal of Human Nutrition, 4(1), pp.1-11.

Slavin, J. L. 2005. Dietary fiber and body weight. Nutrition. 21(3):411 418.

Slavin, J. L. 2008. Position of the American Dietetic Association: health implications of dietary fiber. Journal of the American Dietetic Association, 108(10), 1716-1731.

Subardjo, Y.P., Agustia, F.C., Ramadhan, G.R., Betaditya, D., Sulistyaning, A.R. and Putri, W.A.K., 2018. Indeks Massa Tubuh Dan Profil Sindroma Metabolik Masyarakat Usia Produktif Di Posbindu PTM Kabupaten Banyumas. Jurnal Nutrisia, 20(1), pp.1-5.

Swift, D.L., Johannsen, N.M., Lavie, C.J., Earnest, C.P. and Church, T.S., 2014. The role of exercise and physical activity in weight loss and maintenance. Progress in cardiovascular diseases, 56(4), pp.441-447

Van de Vijver, L.P.L., Van den Bosch, L.M.C., Van den Brandt, P.A. and Goldbohm, R.A., 2009. Whole-grain consumption, dietary fibre intake and body mass index in the Netherlands cohort study. European journal of clinical nutrition, 63(1), p.31.

Wang, H., Steffen, L.M., Zhou, X., Harnack, L. and Luepker, R.V., 2013. Consistency between increasing trends in added-sugar intake and body mass index among adults: the Minnesota Heart Survey, 1980-1982 to 2007 2009. American journal of public health, 103(3), pp.501-507. 